\title{
EFFECT OF FOOD AND PREDATORS ON THE ACTIVITY OF FOUR LARVAL RANID FROGS
}

\author{
Bradley R. Anholt, ${ }^{1,3}$ Earl Werner, ${ }^{2}$ And David K. Skelly ${ }^{2,4}$ \\ ${ }^{1}$ Department of Biology, Erindale College, University of Toronto, Ontario, Canada \\ ${ }^{2}$ Department of Biology, University of Michigan, Ann Arbor, Michigan 48109 USA
}

\begin{abstract}
When animals are more active they encounter both more food and more predators. Thus, activity rates mediate a trade-off between growth rates and predation risk. Models of the trade-off generally, but not exclusively, predict reduced activity when resource availability increases or when predation risk increases. In a laboratory setting, we videotaped larvae of four species of ranid frogs (bullfrog, Rana catesbeiana; green frog, $R$. clamitans; leopard frog, R. pipiens; and wood frog, $R$. sylvatica). Changes in activity level in response to changes in food and predator density were measured. Overall, species reduced both the proportion of time active and swimming speed with increases in resource level and predator density. These effects were additive. Regardless of food level, additional predators reduced activity levels similar amounts in all four species. Larger animals, which are less vulnerable to predation, were more active than smaller animals. Leopard frog and wood frog larvae, which are characteristic of more temporary waters, responded more strongly to variation in food levels than did bullfrog and green frog larvae.
\end{abstract}

Key words: antipredator behavior; anuran larvae; growth rate; movement speed; predation risk; Rana; trade-off.

\section{INTRODUCTION}

A fundamental trade-off that confronts many animals in their daily existence centers around how active they are; i.e., the proportion of time they spend actively moving, and the speed at which this movement takes place. Almost all free-living animals must be active in order to acquire resources and obtain mates, and this activity also makes them more vulnerable to predators. Increased activity has been shown to both increase resource acquisition (reviewed in Werner and Anholt 1993, Lima 1998), and increase encounter rates with predators (Gerritsen and Strickler 1977) or detection by predators (e.g., Gendron and Staddon 1984).

Because behavior under this trade-off determines the survival of the individual and the acquisition of resources necessary for reproduction, activity has potential consequences for population dynamics. Thus, activity can be a fundamental mechanism shaping the consequences of species interactions. For example, activity can determine the competitive abilities of a species and its vulnerability to predators. Moreover, if this behavior is not fixed, but is adjusted to fit local or current circumstances, then behavioral responses can be an important source of trait-mediated indirect effects in ecological communities (Abrams 1984, 1995, Wer-

Manuscript received 3 September 1998; revised 15 July 1999; accepted 13 October 1999; final version received 20 December 1999.

${ }^{3}$ Present address: Department of Biology, University of Victoria, P.O. Box 3020, Station CSC, Victoria, British Columbia V8W 3N5 Canada. E-mail: banholt@uvic.ca

${ }^{4}$ Present address: School of Forestry and Environment, Yale University, New Haven, Connecticut 06511 USA. ner 1992b). For example, reduced activity levels in the presence of a predator can alter the per capita competitive effects of one species on another (Werner and Anholt 1996). Very simple food webs can be replete with trait-mediated indirect effects due to adaptive variation in behavior (Peacor and Werner 1997).

A number of workers have developed theory to predict the expected level of activity under this trade-off (Abrams 1984, 1990, 1991a, b, 1993a, b, McNamara and Houston 1987, 1994, Werner and Anholt 1993, Houston et al. 1993). Predictions, of course, vary with assumptions but several general trends can be seen. (1) Activity is predicted to decline with predation risk which is usually associated with predator density, but also can reflect predator behavior, time of day, or structure of the habitat. (2) Above some minimum food level, long-term increases in food resources should also lead to a decline in foraging activity, although predictions for short-term increases may be different (Abrams 1982, 1984, McNamara and Houston 1994). Decreasing activity with increasing resources is opposite to the predictions by models that do not include the risk of predation (Ware 1975, Norberg 1981, Speakman 1986, Dunbrack and Giguere 1987).

In this study, we examine the activity responses, both speed of movement and proportion of time active, of four species of ranid larvae of more than one size class, to changes in food resource levels and perceived predation risk. Previous studies of prey activity under predation risk have usually provided data on the frequency of movement with almost none providing measures of movement speed (but see Kohler and McPeek 1989, Anholt and Werner 1995). There are reasons to expect 
that these two measures of activity would be separately modified by animals depending on the relative speed of their predators or prey. For example, changing speed leads to the greatest reduction in predation risk when predators are stationary (Skellam 1958, Gerritsen and Strickler 1977). Our experiments also manipulate food and predators simultaneously. Although, many studies have looked at responses to risk, few have examined whether the effect of predators depends on resource availability (e.g., Horat and Semlitsch 1994, Anholt et al. 1996, reviewed in Lima 1998). We predicted that either increasing predator density or resource availability would reduce the activity (frequency of movement and movement speed) of frog larvae. We also predicted that, provided larvae did not stop moving because of very low resource levels, the effect of predators would be present at all food levels.

Predation risk of frog larvae is influenced by size (Caldwell et al. 1980, Travis et al. 1985). In addition, relatively invulnerable size classes are expected to be less sensitive to changes in predation risk. Therefore, we predicted that larger larvae would be more active than small ones.

Finally, this study examines the response of species with widely differing ecological requirements and differing life histories that might be expected to influence the response to resources and predation risk. The four species that we chose to study are distributed along an environmental gradient from permanent to temporary ponds in southern Michigan. Ordered from the most permanent to most temporary habitat species, the species are the bullfrog (Rana catesbeiana), green frog $(R$. clamitans), leopard frog (R. pipiens), and wood frog (R. sylvatica) (Collins and Wilbur 1979, Skelly et al. 1999).

A number of ecological factors vary in concert with the pond permanence gradient that might influence activity responses, including the time available for larval development, resource abundance, and the complement of predators and competitors (Wellborn et al. 1996). Further, these factors can vary from year to year within a pond. This variation both in space and time should select for the ability to adjust activity to current conditions. We predicted that temporary pond species should be less responsive to predators than permanent pond species because habitat drying necessitates rapid growth. We also expected that permanent pond species that can overwinter as larvae, such as the bullfrog and green frog, should be more responsive to predators since they have the option of reducing growth rates and remaining longer in the habitat. By employing these four species we can test the robustness of the predictions of the theory across a number of species. Further, differences in responses of species can be correlated with differences in the environments that they typically experience in time and space, and provide comparative insight into factors selecting for different behavioral tactics.

\section{Methods}

We quantified the activity of the four species in the laboratory in $37.5 \times 24.1 \mathrm{~cm}$ plastic containers filled to a depth of $7 \mathrm{~cm}$ with untreated well water. Each container was equipped with four cylindrical predator cages, $7.5 \times 2.8 \mathrm{~cm}$, one in each corner of the container. The cages were constructed of aluminum wire and plastic mesh with an inner sleeve of fiberglass window screening. Resources for the larvae were a finely ground 3:1 mixture of Purina rabbit chow and Tetramin fish flakes. Predators were nymphs of the dragonfly Anax junius (instars F-1, F-2; 30-40 mm total length). In predator treatments, individual Anax were placed in the cages and, therefore, could not actually prey on the larvae. Each Anax nymph was fed two or three larvae of the species being filmed before being placed in the cages.

We obtained frog larvae for the experiments from cultures maintained outdoors in small wading pools and fed pulverized rabbit chow. Cultures were initiated with egg masses collected from local ponds. The wood frog culture was initiated with two egg masses from Cassandra Bog on the E. S. George Reserve of the University of Michigan $\left(42^{\circ} 28^{\prime} \mathrm{N}, 84^{\circ} 00^{\prime} \mathrm{W}\right)$. Leopard frog and green frog cultures were initiated with multiple egg masses from the experimental ponds on the Reserve. Bullfrog cultures were initiated with egg masses collected from the Michigan Department of Natural Resources' pond facility at Saline, Michigan, USA. Larvae were between Gosner (1960) stages 30-36 (hind limb bud development) at time of the experiment.

We subjected each of the four frog species to one or both of two completely randomized block experimental designs (Table 1 ). The primary design was a $2 \times 4$ factorial with two predator levels, either one or three caged Anax, and four resource levels, either 2\%, 4\%, $8 \%$, or $16 \%$ of initial body mass per day. Each treatment combination was replicated in four blocks. A sample of the population of larvae employed for each experiment was weighed to provide the initial mass of the larvae, and thus to determine the amount of food added to the containers (as a percentage of mean body mass per day). The second experimental design also was a $2 \times 4$ factorial experiment, in this case with two resource levels, $4 \%$ and $16 \%$ of body weight per day, and four predator levels, either zero, one, two, or three Anax per container. The complete design was again replicated four times. In all cases, 10 larvae were placed in each container. Experiments were conducted with two size classes of wood frog, leopard frog, and bullfrog larvae, and three size classes of green frog larvae (Table 1).

Activity was quantified by videotaping the experimental units. The recording was conducted on a shelf that accommodated one block of treatments at a time. Treatments were randomly assigned to positions on the shelf and identified with a tag placed alongside the tank. 
TABlE 1. Mean frog larva mass, food level, and predator number in each experiment.

\begin{tabular}{lcccc}
\hline \hline \multicolumn{1}{c}{ Species } & Starting date & Mass $(\mathrm{mg})$ & $\begin{array}{c}\text { Food levels } \\
(\% \text { body mass/day })\end{array}$ & Predator number \\
\hline Bullfrog & 13 July & 52 & $2,4,8,16$ & 1,3 \\
& 27 July & 64 & 4,16 & $0,1,2,3$ \\
Green frog & 23 June & 20 & $2,4,8,16$ & 1,3 \\
& 6 July & 47 & $2,4,8,16$ & 1,3 \\
\multirow{2}{*}{ Leopard frog } & 20 July & 83 & 4,16 & $0,1,2,3$ \\
& 25 May & 81 & $2,4,8,16$ & 1,3 \\
Wood frog & 15 June & 134 & 4,16 & $0,1,2,3$ \\
& 19 May & 52 & $2,4,8,16$ & 1,3 \\
& 8 June & 183 & $2,4,8,16$ & 1,3 \\
\hline
\end{tabular}

Four cameras were positioned in holes drilled in a shelf above the one holding the experimental containers. These four cameras all fed to a single VCR that taped the experiments. Each camera simultaneously filmed two of the eight experimental containers on the shelf. All cameras were on individual timers; timers were set such that the first camera was activated for a 10 minute period and then turned off while the timer on the next camera then activated that camera. Thus, all cameras were activated in sequence; after all four cameras had filmed for $10 \mathrm{~min}$, the sequence was cycled back to the first camera. This cycle was repeated four times for each block (replicate) of treatments. Thus, each container was filmed for a total of 40 minutes.

Filming commenced on the third day of the experiment and required two days. Block A was filmed in the morning of day three, block B that afternoon, and blocks $\mathrm{C}$ and $\mathrm{D}$ the morning and afternoon of the fourth day. The experimental containers were placed on a table top and each block moved onto the filming shelf at least one hour before filming began. All experiments were conducted under a $14 \mathrm{~h}$ light: $10 \mathrm{~h}$ dark cycle. Temperatures of the containers were measured when they were filmed. The food ration was added daily to the containers. Food was added to the containers at noon on days when filming occurred. Each population was weighed at the end of the experiment and the mean individual mass determined by dividing by the number of surviving larvae. With the exception of the first wood frog experiment, no more than one larva died in any one container, and four or fewer larvae (out of 320) died in any one experiment.

\section{Measurement of activity from films}

We measured the movement speed of larvae between 80 and 161 times $($ median $=150)$ in each experimental unit from the videotaped images. A customized macro written in the computerized image analysis system, Optimas (Media Cybernetics, Seattle, Washington, USA), was used. For each measurement sequence we first marked a reference point on the image and then marked the position of several well separated larvae. We then advanced the videotape exactly three seconds using a jog shuttle to the next image. The reference point was re-marked and the previous position of the larvae was highlighted on the screen by the program. We then marked the new position of the larvae on the image. The change in position of the larvae divided by the elapsed time is our measurement of movement speed. We measured at least 40 pairs of images for each experimental container during the two hour course of filming, with ten pairs separated by one minute in each ten-minute stretch of videotape. A technician unaware of the hypotheses being tested or of the experimental treatments collected all of the measurements.

\section{Data reduction}

Activity.-From each experimental container we wished to extract the proportion of time that the animals were active, and when they were active how fast they were swimming. Unfortunately, the definition of inactive is problematic. If an animal is stationary, the computer operator must make four exact marks in order to return a value of zero. The reference point must be marked exactly correctly twice, and the larva marked in exactly the same way in both video frames. Measurements of stationary objects using this methodology showed us that this occurs only about $5 \%$ of the time (B. Anholt, unpublished data). We have implemented a Bayesian algorithm to categorize an individual observation as being stationary or moving. We have found this to make fewer assignment errors than using an arbitrary cutoff (B. Anholt, unpublished data) because individual species differ in how likely they are to be active. Our prior estimates for the probability of being active were based on published work (Werner 1991, $1992 a$ ). We fitted a negative exponential distribution to movement speeds previously measured on bullfrog larvae (Anholt and Werner 1995) using the method of moments. We fitted a two parameter gamma distribution to our measurements of stationary objects using the method of moments for a prior distribution of measurement errors. For each individual measurement of movement speed we then used Bayes' theorem to compare the odds that the observation was of a stationary larva plus measurement error with the odds that the observation was of a moving larva plus measurement error. This algorithm was implemented as a series of macros in S-Plus (1997), which are available from the senior author. 
TABLE 2. Analysis results of logit(proportion moving) and $\log$ (mean swimming speed) of larvae from all species combined as a function of food availability, predator density, and starting mass.

\begin{tabular}{|c|c|c|c|c|c|c|c|c|c|c|}
\hline \multirow[b]{3}{*}{ Effect } & & & & \multicolumn{7}{|c|}{ ANOVA } \\
\hline & \multicolumn{3}{|c|}{ MANOVA } & \multicolumn{4}{|c|}{ Proportion moving } & \multicolumn{3}{|c|}{ Swimming speed } \\
\hline & $F \dagger$ & $\frac{\text { MANO }}{\mathrm{df} \neq}$ & $P$ & df & $\begin{array}{l}\text { Sum of } \\
\text { squares }\end{array}$ & $F$ & $P$ & $\begin{array}{l}\text { Sum of } \\
\text { squares }\end{array}$ & $F$ & $P$ \\
\hline Species & 19.97 & 6,536 & $<0.0001$ & 3 & 13.25 & 7.55 & $<0.0001$ & 25.93 & 38.42 & $<0.0001$ \\
\hline Food availability & 23.97 & 2,267 & $<0.0001$ & 1 & 28.12 & 48.10 & $<0.0001$ & 3.55 & 15.78 & $<0.0001$ \\
\hline Predator density & 41.34 & 2,267 & $<0.0001$ & 1 & 48.32 & 82.66 & $<0.0001$ & 7.65 & 34.01 & $<0.0001$ \\
\hline Starting mass & 55.49 & 2,267 & $<0.0001$ & 1 & 64.72 & 110.71 & $<0.0001$ & 10.67 & 47.43 & $<0.0001$ \\
\hline Starting $\times$ Food & 4.81 & 6,536 & 0.0001 & 3 & 12.31 & 7.02 & 0.0001 & 5.89 & 8.74 & $<0.0001$ \\
\hline Species $\times$ Pred & 0.74 & 6,536 & 0.61 & 3 & 2.28 & 1.30 & 0.27 & 0.53 & 0.78 & 0.51 \\
\hline Food $\times$ Pred & 0.51 & 2,267 & 0.60 & 1 & 0.03 & 0.06 & 0.80 & 0.20 & 0.88 & 0.35 \\
\hline Species $\times$ St. mass & 6.62 & 6,536 & $<0.0001$ & 3 & 12.80 & 7.30 & 0.0001 & 5.05 & 7.48 & $<0.0001$ \\
\hline $\begin{array}{l}\text { Species } \times \text { Food } \\
\times \text { Pred }\end{array}$ & 0.97 & 6,536 & 0.44 & 3 & 0.33 & 0.19 & 0.91 & 0.52 & 0.77 & 0.51 \\
\hline Residuals & & & & 268 & 156.68 & & & 60.29 & & \\
\hline
\end{tabular}

$\dagger$ Approximate $F$

$\ddagger$ Degrees of freedom numerator, denominator.

If an animal was (declared to be) moving, then the observed value was included in the average speed of moving animals. This reduced our data set from more than 180 measurements per container to just two; the proportion of observations where the animals were moving, and the average speed when moving.

Mass change.-We calculated the rate of mass change as a daily proportion of body mass using the model: final mass $=$ initial mass $\times(1+\text { rate })^{\text {days }}$. Solving for "rate" gives the formula: rate $=\exp \{[\log$ (final mass $)-\log$ (initial mass)]/days $\}-1$. The residuals from these analyses did not differ from a normal distribution and standard transformations did not improve the fit to normality.

\section{Data analysis}

We analyzed the two activity variables, proportion of time active and average speed when active, using multivariate ANOVA in S-Plus. MANOVA was followed by univariate ANOVA for each of the response variables to partition the effects. We transformed proportion of observations active using the log:odds ratio $(\operatorname{logit}=\log [\mathrm{P} /(1-\mathrm{P})])$ which improved the fit of the residuals to normality. We used the logarithm of average speed to improve the fit of the residuals to normality. A non-significant interaction term implies that effects are additive (subject to Type 2 error) on the scale of measurement of the response variable. Not surprisingly, untransformed response variables do show some significant interactions.

We first analyzed the activity data by combining all experiments in a single analysis with species as a fixed effect. We accounted for different time blocks using the starting mass of the larvae in the experiment. We did not include the designed blocks because this would subsume any species effect. Combining the data this way allows us to test for the generality of the treatment effect across species, increases our power to detect an overall treatment effect, as well as compare species responses to the treatments.

We then went on to analyze the responses of individual species in more detail. Experiments conducted on the same species at different times were treated as time blocks. Designed experimental blocks associated with filming were nested within time blocks. Significant effects of time can be interpreted as an effect due to some condition of the larvae such as size or development but could also be attributable to differences in environmental or experimental conditions that obtained at that time. However, the constraints of amphibian life histories do not allow us to randomize developmental stage with date to eliminate the confounding of size with time. We analyzed the rate of mass change for each species using the same design as the activity measures.

An underlying assumption of models proposing a trade-off between growth and mortality is that increased activity leads to higher resource acquisition. To examine this assumption we tested whether change in mass for any experimental unit could be predicted on the basis of the activity of those individuals after we accounted for the effect of food added to the arena.

\section{RESUlTs \\ Activity}

Overall analysis. - A combined analysis of all species together uncovered significant differences among species that were independent of differences in initial mass (Table 2). Green frog larvae were the most active, followed by bullfrog, leopard frog, and wood frog larvae (Fig. 1). Tukey multiple comparisons showed that green frog larvae were active more of the time than all other species, and that wood frog larvae were active less often than the other species. Bullfrog and leopard frog larvae were intermediate and not significantly different from each other. Swimming speed rank was near- 

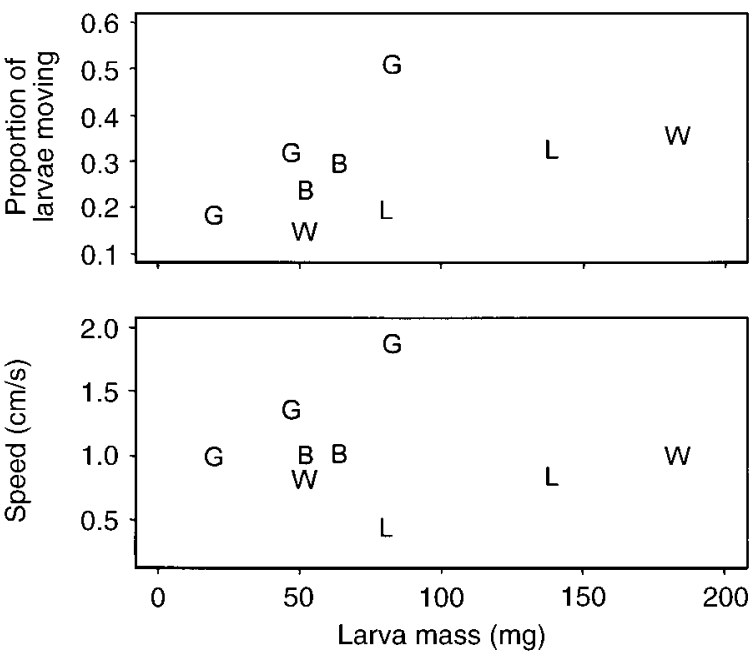

FIG. 1. Overall activity for each experiment plotted as a function of starting mass. Species are denoted by the first letter of their common name.

ly the same as the proportion of time active. Green frog larvae swam the fastest followed by bullfrog, wood frog and leopard frog larvae (Fig. 1). All the species were significantly different from each other as determined by Tukey's multiple comparisons. Larger animals were more active than smaller ones (Fig. 1), but the effect of increased starting mass differed among species (species $\times$ starting mass interaction term).

After accounting for species and starting mass differences we still found that increased food level led to reduced probability of movement and reduced swimming speed. Similarly, there was an overall reduction in activity with increasing predator density. Although the effect of food differed among species (species $X$ food interaction term) the effect of predators was similar across species. Additional predators reduced the probability of movement and swimming speed regardless of food level (Figs. 2-5; Table 2).

Most of the trends found in the overall analysis were consistent with those found in the individual species analyses. Below we outline departures from these trends for each of the species tested. Analyses of individual species had much lower power because of the reduced sample size.

Bullfrogs.-Increased food level significantly reduced the proportion of time active as in the full analysis, but not the average swimming speed (Fig. 2; Table $3)$. There were also no detectable differences between the two size classes tested. However, the two sizes differed by only $12 \mathrm{mg}$.

Green frogs.-Proportion of time active declined with both food level and predator level as in the overall analysis (Fig. 3; Table 4). However, small larvae reduced activity more in the presence of predators than
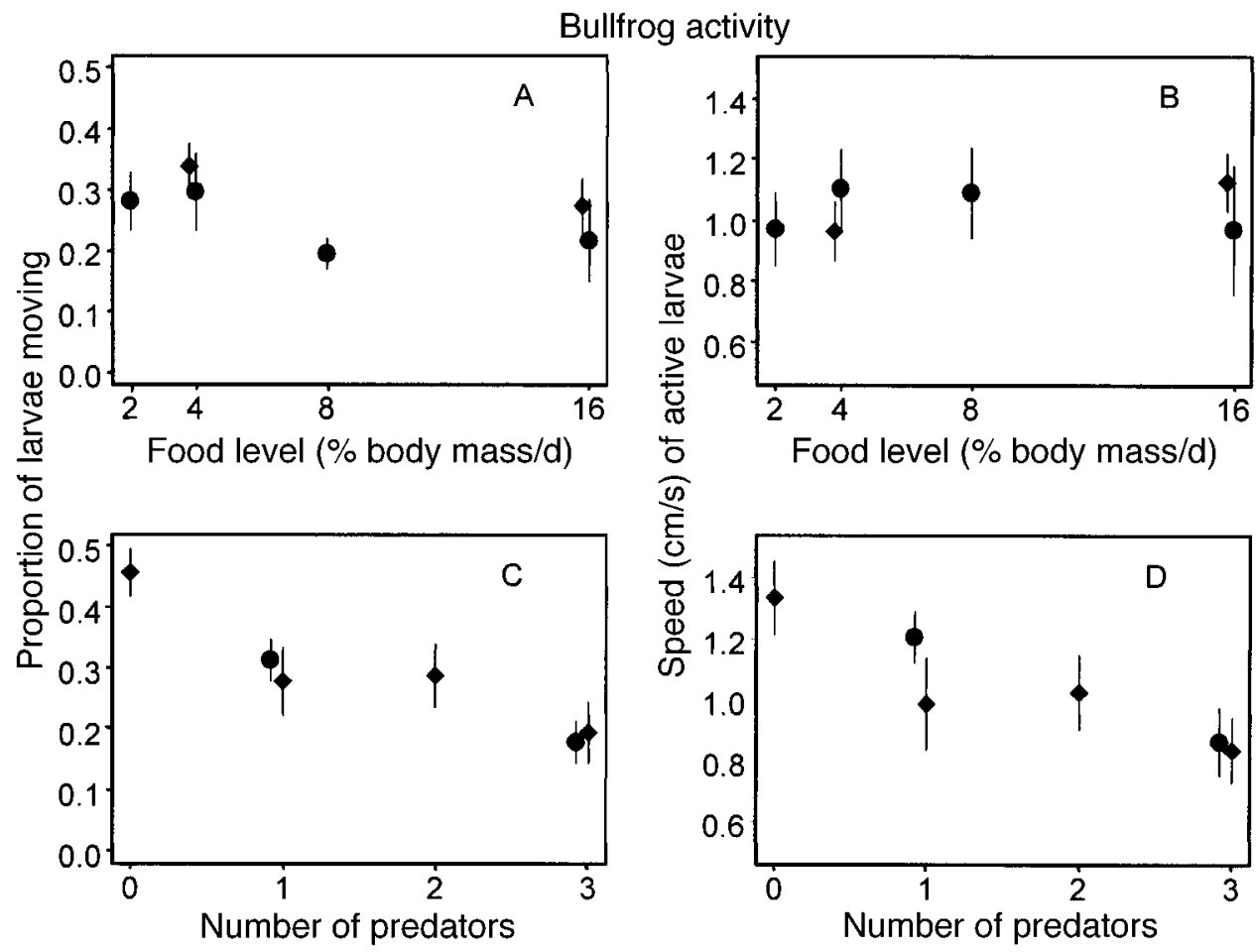

FIG. 2. Proportion of focal bullfrog larvae moving, and swimming speed of the active larvae (mean $\pm 1 \mathrm{SE}$ ) as a function of food availability and predator density. Mean values for food levels were determined across predator densities, and mean values for predator density were determined across food levels. Circles indicate results from the earlier experiment with smaller animals, and diamonds denote the later experiment. 


\section{Green frog activity}
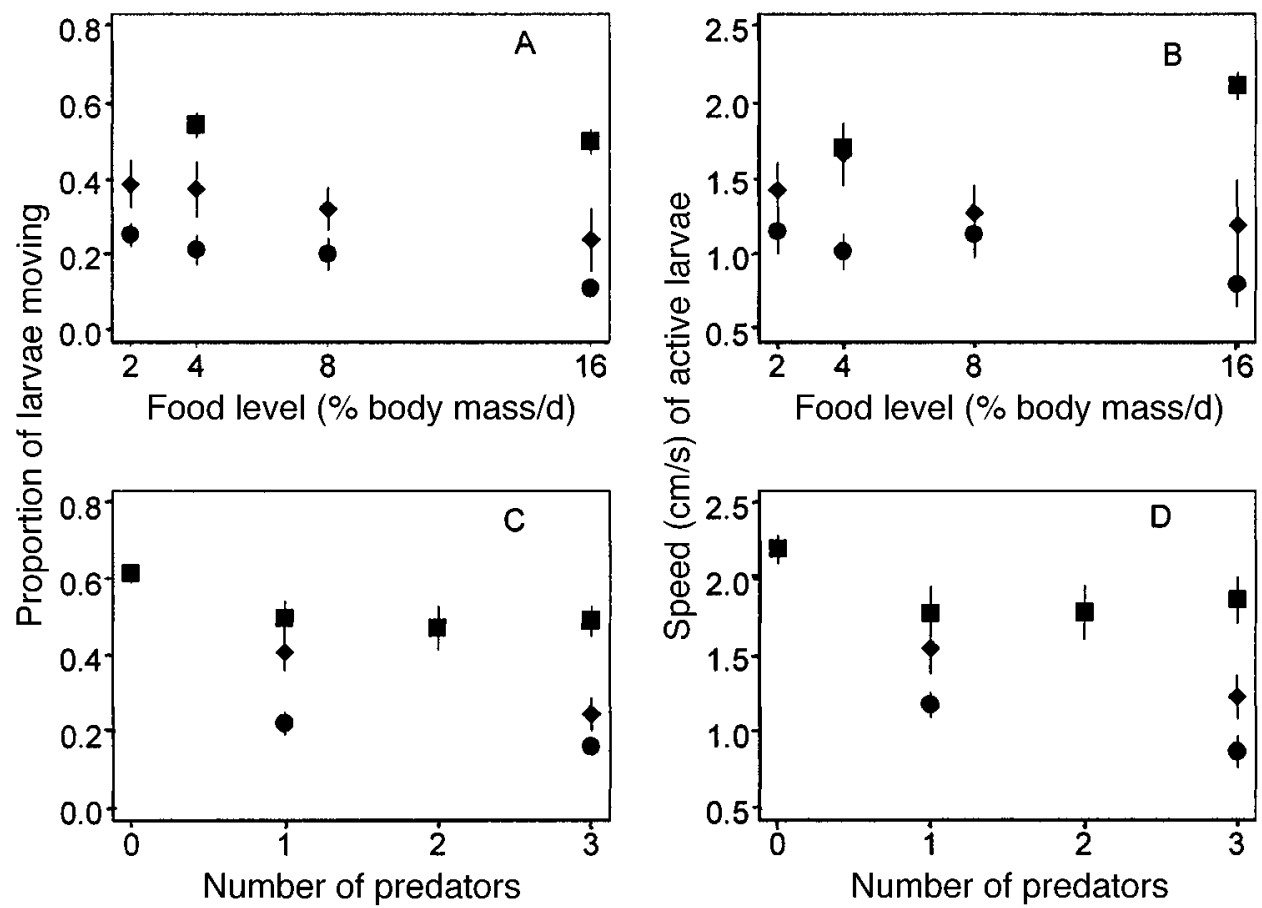

FIG. 3. Proportion of focal green frog larvae moving, and swimming speed of the active larvae (mean $\pm 1 \mathrm{SE}$ ) as a function of food availability and predator density. Mean values for food levels were determined across predator densities, and mean values for predator density were determined across food levels. Circles indicate results from the first experiment with smallest animals, diamonds indicate the middle experiment, and squares indicate the last experiment with largest animals.

did large larvae, yielding a significant interaction between starting size and predator treatment. There was no overall effect of food on swimming speed, but there was a strong interaction between experiment and food level on swimming speed. While swimming speed declined in the first two experiments $\left(F_{1,26}=5.04 ; P=\right.$ 0.03 and $F_{1,26}=5.20 ; P=0.03$ respectively), it actually increased in the third experiment $\left(F_{1,26}=12.20 ; P=\right.$ $0.002)$

Leopard frog.- The effect of food levels and predators were the same as that in the overall analysis (Fig. 4; Table 5).

Wood frog.-The effect of food was similar to the overall analysis but there were no detectable effects of predators (Fig. 5; Table 6) even though there was no species $\times$ predator interaction term in the overall analysis (Table 2).

\section{Mass gain}

Overall analysis. - The daily rate of mass gain increased with food ration (Fig. 6; Table 7). The effect of predators was more complex. At high food levels, increased predator density decreased mass gain, but at low food levels, the opposite effect was observed (Fig. 6). Thus, there was no overall effect of predators on mass gain, but a strong interaction term (Table 7). Analyzing each species separately showed that only wood frogs deviated from this overall pattern. Wood frog larvae showed no detectable predator main effect or predator $\times$ food level interaction (Fig. 6; Table 8). Dividing the data into two halves with high and low food levels and reanalyzing confirmed this result. When the larvae were provided $8 \%$ or $16 \%$ body mass of food per day, increased predator density reduced mass gain $\left(F_{1,125}=12.0 ; P<0.001\right)$. When the larvae were provided $2 \%$ or $4 \%$ body mass of food per day, increased predator density increased mass gain $\left(F_{1,125}=15.7 ; P\right.$ $<0.001)$. There was no detectable overall effect of the proportion of time active on mass gain, but faster swimming animals did gain more mass, even after accounting for the effects of predator and food treatments on activity levels (Table 7). Rate of mass gain also differed among species (Table 7). Tukey's multiple comparisons showed that bullfrog and green frog larvae gained less mass than leopard frog and wood frog larvae (Fig. 7). The food $\times$ species interaction term showed that individual species differed in their response to the food treatment (Table 7). The improvement in mass gain with additional food was highest in leopard frog larvae followed by bullfrog, green frog, and wood frog larvae (Fig. 6).

\section{DISCUSSION}

In almost every case the activity levels of the larvae conformed to the predictions of theory. When more 


\section{Leopard frog activity}
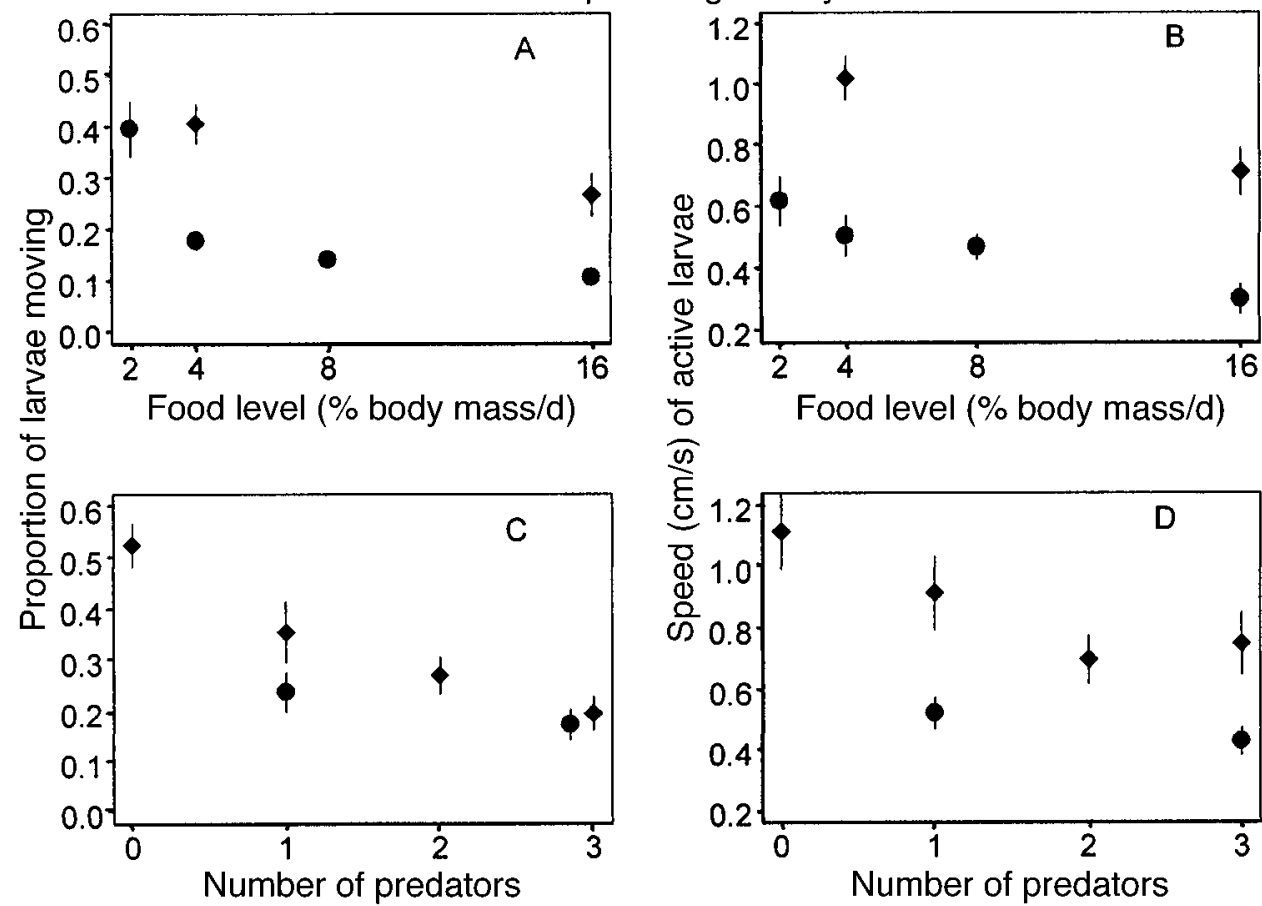

FIG. 4. Proportion of focal leopard frog larvae moving, and swimming speed of the active larvae (mean $\pm 1 \mathrm{SE}$ ) as a function of food availability and predator density. Mean values for food levels were determined across predator densities, and mean values for predator density were determined across food levels. Circles indicate results from the earlier experiment with smaller animals, and diamonds denote later experiment.

food was available or when predators were more abundant, larvae moved less often, and when they did move, they moved more slowly. This pattern suggests that the animals are simultaneously sensitive to risks from predation and gains from growth. Note that the effects of the two manipulations are additive; there are no statistical interaction terms between the food manipulation or predator manipulation for any measure of activity, for any species, or for any size class (time). Even when the power of the test was maximized by combining all species together, no interaction term could be detected between food level and predator level. The larvae reduced their activity rate when predator density was increased at high food levels and at low food levels. A change in scale of measurement would create an interaction term, but would not alter the fact of reduced activity at all food levels with increased predator density (with the exception of one size class of green frog larvae). Increased activity levels at lower food levels is consistent with the universal observation that animals take greater risks if on low reserves (reviewed in Lima 1998). However, even at low food levels these animals are not insensitive to predator density, increasing cues from predators will still elicit a response.

At very low food levels where the additional energetic costs of activity to acquire food are too great, theory also predicts that activity should decline rather than increase (Abrams 1982, 1984, McNamara and
Houston 1994). Bullfrog larvae did lose weight at the lowest food level and they also had reduced (not significantly) swimming speeds at the lowest food level. Leopard frog larvae also failed to gain mass at the lowest food level but there was no evidence of reduced activity in their case. Even at the lowest food level tested, green frog and wood frog larvae gained $5 \%$ body mass per day. We tested for an intermediate maximum of activity levels using second-order terms in the predictive model, but none of the coefficients were significant (all $P>0.3$ ).

The larvae also tended to be more active in later experiments. Because the second set of experiments occurred later in development with larger larvae, we interpret this outcome as being consistent with reduced mortality risk for larger larvae (see also Werner 1992a, Eklov and Werner 2000). We cannot entirely eliminate alternative explanations due to confounding body size with time of year or changes in experimental conditions. Water temperature varied between $19.9^{\circ}$ and $21.6^{\circ} \mathrm{C}$ over the course of the experiments but not consistently with changes in body size. Larger larvae have higher burst speeds (Wassersug 1989, J. M. L. Richardson, unpublished data). However, the swimming speeds measured in these experiments are very much less and only $10 \%$ to $20 \%$ of sustained swimming speeds for anuran larvae (Wassersug 1989). Moreover, increases in the proportion of time active with body 


\section{Wood frog activity}
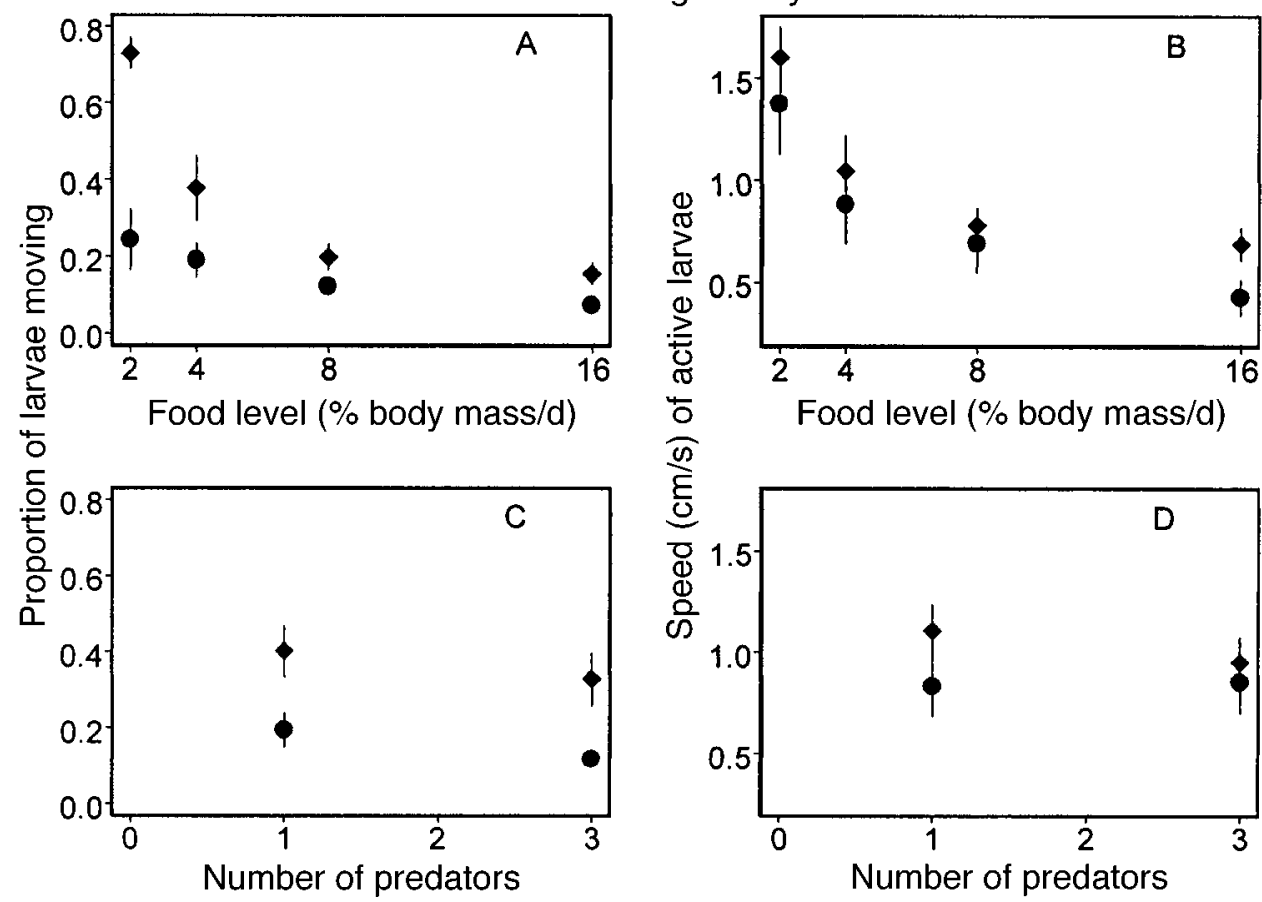

FIG. 5. Proportion of focal wood frog larvae moving, and swimming speed of the active larvae (mean \pm 1 SE) as a function of food availability and predator density. Mean values for food levels were determined across predator densities, and mean values for predator density were determined across food levels. Circles indicate results from the earlier experiment with smaller animals, and diamonds denote the later experiment.

size are not predicted on biomechanical grounds. Changes in activity with body size are to be expected because larger animals are less vulnerable to predation in many aquatic taxa (Stein and Magnuson 1976, Brodie and Formanowicz 1983, Werner and Gilliam 1984, Werner 1992a, Peacor and Werner 1997). The consequences of this prediction were tested in a competition experiment between large and small bullfrog larvae
(Werner and Anholt 1996). In that experiment, we found that in the presence of predators small larvae reduced their feeding rate and grew more slowly. However, the larger, relatively invulnerable size class did not reduce activity, and thereby gained a competitive advantage (see also Peacor and Werner 1997). Similar results have also been obtained in size-structured fish communities (Werner et al. 1983, Tonn et al. 1992).

TABLE 3. MANOVA results of logit(proportion moving) and $\log$ (mean swimming speed) of bullfrog larvae as a function of food availability and predator density.

\begin{tabular}{|c|c|c|c|c|c|c|c|c|c|c|}
\hline \multirow[b]{4}{*}{ Factor } & \multirow{3}{*}{\multicolumn{3}{|c|}{ MANOVA }} & \multicolumn{7}{|c|}{ ANOVA } \\
\hline & & & & \multirow[b]{3}{*}{ df } & \multicolumn{3}{|c|}{ Proportion moving } & \multicolumn{3}{|c|}{ Swimming speed } \\
\hline & & & & & Sum of & & & Sum of & & \\
\hline & $F \dagger$ & $\mathrm{df} \neq$ & $P$ & & squares & $F$ & $P$ & squares & $F$ & $P$ \\
\hline Time & 2.71 & 2,49 & 0.076 & 1 & 2.11 & 3.71 & 0.060 & 0.022 & 0.14 & 0.71 \\
\hline Food availability & 6.57 & 2,49 & 0.003 & 1 & 3.51 & 6.17 & 0.016 & 0.007 & 0.04 & 0.84 \\
\hline Predator density & 11.81 & 2,49 & $<0.0001$ & 1 & 13.68 & 24.02 & $<0.0001$ & 2.167 & 13.04 & 0.0007 \\
\hline Time $\times$ Food & 1.18 & 2,49 & 0.31 & 1 & 0.08 & 0.14 & 0.71 & 0.300 & 1.80 & 0.18 \\
\hline Time $\times$ Pred & 0.35 & 2,49 & 0.70 & 1 & 0.02 & 0.04 & 0.84 & 0.089 & 0.54 & 0.47 \\
\hline Food $\times$ Pred & 0.19 & 2,49 & 0.82 & 1 & $<0.01$ & $<0.01$ & 0.95 & 0.040 & 0.24 & 0.63 \\
\hline Block IN Time & 1.55 & 12,100 & 0.12 & 6 & 7.77 & 2.27 & 0.051 & 1.472 & 1.47 & 0.21 \\
\hline $\begin{array}{l}\text { Time } \times \text { Food } \\
\times \text { Pred }\end{array}$ & $<0.01$ & 2,49 & 0.99 & 1 & $<0.01$ & $<0.01$ & 0.94 & 0.001 & $<0.01$ & 0.94 \\
\hline Residuals & & & & 50 & 28.47 & & & 8.308 & & \\
\hline
\end{tabular}

Note: Both experiments are combined in the same analysis, with the two experiments used as time blocks.

$\dagger$ Approximate $F$

$\ddagger$ Degrees of freedom numerator, df denominator. 
TABLE 4. MANOVA results of logit(proportion moving) and $\log ($ mean swimming speed) of green frog larvae as a function of food availability and predator density.

\begin{tabular}{|c|c|c|c|c|c|c|c|c|c|c|}
\hline \multirow[b]{4}{*}{ Factor } & & & & \multicolumn{7}{|c|}{ ANOVA } \\
\hline & \multirow{2}{*}{\multicolumn{3}{|c|}{ MANOVA }} & \multicolumn{4}{|c|}{ Proportion moving } & \multicolumn{3}{|c|}{ Swimming speed } \\
\hline & & & & \multirow[b]{2}{*}{ df } & \multirow{2}{*}{$\begin{array}{l}\text { Sum of } \\
\text { squares }\end{array}$} & \multirow[b]{2}{*}{$F$} & \multirow[b]{2}{*}{$P$} & \multirow{2}{*}{$\begin{array}{l}\text { Sum of } \\
\text { squares }\end{array}$} & \multirow[b]{2}{*}{$F$} & \multirow[b]{2}{*}{$P$} \\
\hline & $F_{\dagger}^{\dagger}$ & $d f \ddagger$ & $P$ & & & & & & & \\
\hline Time & 17.42 & 4,150 & $<0.0001$ & 2 & 43.74 & 54.47 & $<0.0001$ & 7.49 & 33.16 & $<0.0001$ \\
\hline Food availability & 11.13 & 2,74 & 0.0001 & 1 & 6.51 & 16.22 & 0.0001 & 0.36 & 3.20 & 0.08 \\
\hline Predator density & 10.11 & 2,74 & 0.0001 & 1 & 7.15 & 17.81 & $<0.0001$ & 1.32 & 11.72 & 0.001 \\
\hline Time $\times$ Food & 3.90 & 4,150 & 0.005 & 2 & 1.95 & 2.43 & 0.09 & 1.77 & 7.83 & 0.0008 \\
\hline Time $\times$ Pred & 1.21 & 4,150 & 0.31 & 2 & 1.60 & 1.99 & 0.14 & 0.34 & 1.50 & 0.23 \\
\hline Food $\times$ Pred & 0.65 & 2,74 & 0.53 & 1 & $<0.01$ & 0.0009 & 0.98 & 0.07 & 0.59 & 0.44 \\
\hline Block IN Time & 2.95 & 18,150 & 0.0002 & 9 & 10.00 & 2.77 & 0.008 & 5.69 & 5.59 & $<0.0001$ \\
\hline $\begin{array}{c}\text { Time } \times \text { Food } \\
\times \text { Pred }\end{array}$ & 0.67 & 4,150 & 0.62 & 2 & 0.71 & 0.88 & 0.41 & 0.17 & 0.76 & 0.47 \\
\hline Residuals & & & & 75 & 30.11 & & & 8.47 & & \\
\hline
\end{tabular}

Note: Both experiments are combined in the same analysis with the two experiments used as time blocks.

$\dagger$ Approximate $F$

$\ddagger$ Degrees of freedom numerator, denominator.

There were two results from our experiments that were inconsistent with other experiments that we have conducted on these species. (1) Green frog larvae were the most active species in these experiments. This is a surprising result; in all previous studies that we have conducted, the green frog was less active than the bullfrog (Werner 1991, Werner 1992a, Relyea 1998, Relyea and Werner 1999, Eklov and Werner 2000). Previous studies estimated proportion of active animals from instantaneous visual samples, whereas we have followed animals using videotape records. Green frog larvae were also found to be more active in another study that sampled using videotape (J. M. L. Richardson, unpublished data). This may be a methodological issue that needs to be resolved. However, even though green frog larvae were surprisingly active (in our experience), they still responded to food and predators in the directions predicted; they were less active at increased food and predator levels, with no interaction between the two treatments. (2) Although when all species were analyzed together there was a significant reduction in activity in the presence of predators and there was no evidence that this effect depended on species identity (no species $\times$ predator interaction term), analysis of the activity of wood frog larvae could not detect an effect of predator density. It seems likely that this result is simply a lack of power due to the type of experiments that we conducted on the wood frogs. This was the only species where both experiments consisted of two predator levels (one and three Anax nymphs) and no zero predator treatment. There is a tendency for probability of movement to decline from the one to three predator treatment, but the trend was not significant. Other experiments conducted at this site with wood frogs which include the zero predator treatment, consistently show strong, significant declines in activity levels in the presence of Anax (e.g., Relyea 1998, Van Buskirk and Relyea 1999). Also, previous experiments

TABLE 5. MANOVA results of logit(proportion moving) and $\log$ (mean swimming speed) of leopard frog larvae as a function of food availability and predator density.

\begin{tabular}{|c|c|c|c|c|c|c|c|c|c|c|}
\hline \multirow[b]{4}{*}{ Factor } & \multirow{3}{*}{\multicolumn{3}{|c|}{ MANOVA }} & \multicolumn{7}{|c|}{ ANOVA } \\
\hline & & & & \multirow[b]{3}{*}{$\mathrm{df}$} & \multicolumn{3}{|c|}{ Proportion moving } & \multicolumn{3}{|c|}{ Swimming speed } \\
\hline & & & & & Sum of & & & Sum of & & \\
\hline & $F \dagger$ & $\mathrm{df} \ddagger$ & $P$ & & squares & $F$ & $P$ & squares & $F$ & $P$ \\
\hline Time & 25.40 & 2,49 & $<0.0001$ & 1 & 8.64 & 28.92 & $<0.0001$ & 6.31 & 44.98 & $<0.0001$ \\
\hline Food availability & 23.12 & 2,49 & $<0.0001$ & 1 & 12.59 & 42.17 & $<0.0001$ & 3.42 & 24.44 & $<0.0001$ \\
\hline Predator density & 17.25 & 2,49 & $<0.0001$ & 1 & 10.48 & 35.09 & $<0.0001$ & 1.26 & 8.96 & 0.004 \\
\hline Time $\times$ Food & 1.29 & 2,49 & 0.28 & 1 & 0.78 & 2.61 & 0.11 & 0.11 & 0.77 & 0.39 \\
\hline Time $\times$ Pred & 3.31 & 2,49 & 0.04 & 1 & 1.86 & 6.21 & 0.02 & 0.03 & 0.22 & 0.64 \\
\hline Food $\times$ Pred & 0.20 & 2,49 & 0.82 & 1 & $<0.01$ & $<0.01$ & 0.98 & 0.05 & 0.34 & 0.56 \\
\hline Block IN Time & 0.68 & 12,100 & 0.77 & 6 & 0.80 & 0.45 & 0.84 & 0.78 & 0.93 & 0.48 \\
\hline $\begin{array}{l}\text { Time } \times \text { Food } \\
\times \text { Pred }\end{array}$ & 0.58 & 2,49 & 0.56 & 1 & 0.07 & 0.24 & 0.63 & 0.17 & 1.18 & 0.28 \\
\hline Residuals & & & & 50 & 14.93 & & & 7.01 & & \\
\hline
\end{tabular}

Note Both experiments are combined in the same analysis, with the two experiments used as time blocks.

$\dagger$ Approximate $F$

$\ddagger$ Degrees of freedom numerator, denominator. 
TABLE 6. MANOVA results of logit(proportion moving) and $\log$ (mean swimming speed) of wood frog larvae as a function of food availability and predator density.

\begin{tabular}{|c|c|c|c|c|c|c|c|c|c|c|}
\hline \multirow[b]{4}{*}{ Factor } & \multirow{3}{*}{\multicolumn{3}{|c|}{ MANOVA }} & \multicolumn{7}{|c|}{ ANOVA } \\
\hline & & & & \multirow[b]{3}{*}{ df } & \multicolumn{3}{|c|}{ Proportion moving } & \multicolumn{3}{|c|}{ Swimming speed } \\
\hline & & & & & \multirow{2}{*}{$\begin{array}{l}\text { Sum of } \\
\text { squares }\end{array}$} & \multirow[b]{2}{*}{$F$} & \multirow[b]{2}{*}{$P$} & \multirow{2}{*}{$\begin{array}{l}\text { Sum of } \\
\text { squares }\end{array}$} & \multirow[b]{2}{*}{$F$} & \multirow[b]{2}{*}{$P$} \\
\hline & $F \dagger$ & $\mathrm{df} \neq$ & $P$ & & & & & & & \\
\hline Time & 14.03 & 2,49 & $<0.0001$ & 1 & 26.59 & 26.97 & $<0.0001$ & 2.39 & 3.15 & 0.02 \\
\hline Food availability & 16.14 & 2,49 & $<0.0001$ & 1 & 31.12 & 31.57 & $<0.0001$ & 8.40 & 20.95 & $<0.0001$ \\
\hline Predator density & 1.34 & 2,49 & 0.27 & 1 & 2.51 & 2.54 & 0.12 & 0.02 & 0.53 & 0.47 \\
\hline Time $\times$ Food & 6.01 & 2,49 & 0.005 & 1 & 3.20 & 3.24 & 0.08 & 0.47 & 1.17 & 0.28 \\
\hline Time $\times$ Pred & 0.28 & 2,49 & 0.76 & 1 & 0.04 & 0.04 & 0.85 & 0.07 & 0.18 & 0.68 \\
\hline Food $\times$ Pred & 1.58 & 2,49 & 0.22 & 1 & 0.12 & 0.12 & 0.73 & 0.48 & 1.22 & 0.28 \\
\hline Block IN Time & 1.91 & 12,100 & 0.04 & 6 & 4.86 & 0.82 & 0.56 & 4.59 & 1.91 & 0.10 \\
\hline Time $\times$ Food & 0.62 & 2,49 & 0.54 & 1 & 0.28 & 0.29 & 0.60 & 0.48 & 1.21 & 0.28 \\
\hline Residuals & & & & 50 & 49.30 & & & 20.04 & & \\
\hline
\end{tabular}

Note: Both experiments are combined in the same analysis with the two experiments used as time blocks.

$\dagger$ Approximate $F$.

$\ddagger$ Degrees of freedom numerator, denominator.

with wood frogs where we have manipulated predator density have shown that at high predator density the larvae have a lower per predator mortality rate consistent with reductions in activity (Anholt and Werner 1998).

One of the fundamental predictions of theories that resolve the trade-off between growth rate and mortality rate is that reduced activity levels in the face of predation risk have an attendant cost in reduced resource acquisition. At high food levels, we found that increasing predator density reduced growth rate, and that within treatment levels, relatively inactive replicates had lower growth rates. However, we also found that at lower food levels, additional predators actually increased growth rates. Predators produce organic wastes that can support bacterial growth. Particularly at low food levels, this may provide additional resources to support larval growth. If we could manipulate larvae's

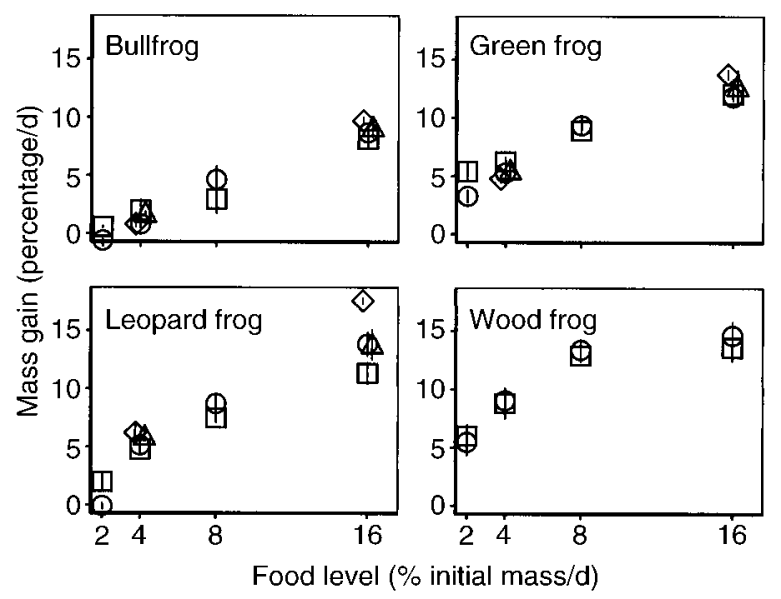

FIG. 6. Rate of mass gain ( $\pm 1 \mathrm{SE}$ ) by the larvae of the four species as a function of food ration and the number of caged predators present: circle $=$ no predators, triangle $=$ one predator, diamond $=$ two predators, square $=$ three predators . perceptions of risk without adding predator wastes we might be able to detect these costs. To do this, we must first determine more exactly how larvae are detecting predators and evaluating risk.

In our experiments, the activity and speed responses to food were weaker in the more permanent water species (bullfrogs and green frogs) than in the more temporary water species (wood frogs and leopard frogs). Temporary pond species must grow and mature to metamorphosis before pond drying occurs. They may be selected to arrive at a balance of the trade-off that weights resource levels more heavily than predation risk. Presumably, they must increase activity more dramatically at low food levels to achieve a growth rate adequate to metamorphose before ponds dry. The more permanent pond species on the other hand are typically found in environments that harbor greater predator densities and diversity (Wellborn et al. 1996, Skelly 1997, Skelly et al. 1999). These species may weight the balance more to predation risk because they have the option of remaining in the habitat and overwintering. Bullfrog and green frog larvae that are not constrained to a single season to complete development then might be less sensitive to food limitation. These expectations are broadly consistent with models of foraging under predation risk that explicitly incorporate finite time horizons (Werner and Anholt 1993, McNamara and Houston 1994). For any given size, these models predict that animals with more time left before they must metamorphose will be less active.

Our data do not suggest, however, that bullfrog and green frog larvae are more sensitive than those of wood frogs and leopard frogs to variation in predator density. Relyea and Werner (1999) also found that the more temporary pond species, wood frogs and leopard frogs, responded morphologically to Anax in similar ways by increasing tail fin depth and decreasing body size, whereas the permanent pond species, bullfrog and 
TABLE 7. Analysis of mass gain for all species combined as a function of the experimental treatments of food availability, predator density, and starting mass, as well as the effect of logit(proportion moving) and $\log$ (mean swimming speed) within a treatment.

\begin{tabular}{lcccc}
\hline \hline \multicolumn{1}{c}{ Treatment } & df & $\begin{array}{c}\text { Sum of } \\
\text { squares }\end{array}$ & $F$ & $P$ \\
\hline Starting mass & 1 & 0.0059 & 15.0 & 0.0001 \\
Food availability & 1 & 0.3253 & 819.2 & $<0.0001$ \\
Predator density & 1 & $<0.0001$ & 0.03 & 0.85 \\
Species & 3 & 0.1745 & 146.5 & $<0.0001$ \\
Proportion moving & 1 & 0.0004 & 0.9 & 0.34 \\
Swimming speed & 1 & 0.0019 & 4.9 & 0.03 \\
Food X Pred & 1 & 0.0077 & 19.5 & $<0.0001$ \\
Food X Species & 3 & 0.0067 & 5.6 & 0.001 \\
Pred X Species & 3 & 0.0055 & 4.6 & 0.004 \\
Food $\times$ Pred & 3 & 0.0012 & 1.0 & 0.40 \\
$\quad \times$ Species & & & & \\
Residuals & 269 & 0.1068 & & \\
\hline
\end{tabular}

green frog, responded very differently by reducing tail fin length and altering body dimensions. The former suite of morphological responses have been shown to be adaptations to reduce vulnerability to Anax (McCollum and Van Buskirk 1996, Van Buskirk et al. 1997, Relyea 1998) and this again may be a way to maintain activity to ensure adequate growth rates while responding morphologically rather than behaviorally to the presence of predators.

Our data on mass gain as a function of food level also exhibit several trends that would repay further investigation. First, two of the species (green frog and wood frog) clearly manage significant growth on the $2 \%$ food level of about $5 \%$ wet mass gain per day. However, the bullfrog and leopard frog larvae exhibit virtually no growth at that food level. These results may have interesting implications for competitive interactions. Species that can continue to grow at low food levels will be dominant where competition is extreme (O'Brien 1974, Tilman 1982). Our results suggest that in the species pairs that are often found together and may compete (bull/green and wood/leopard) one of the species has a clear advantage at low food

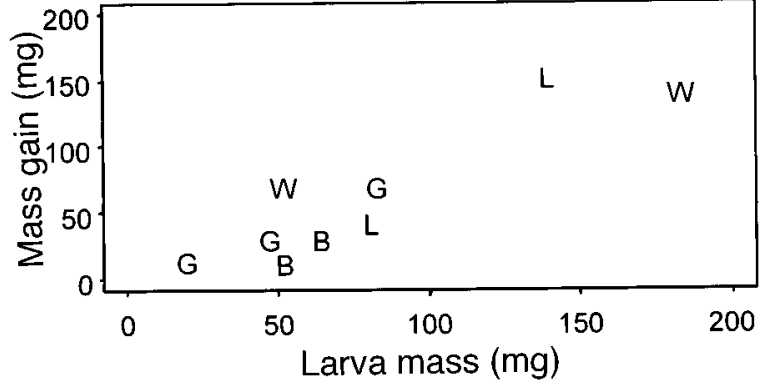

FIG. 7. Rate of mass change as a function of starting mass. Species are denoted by the first letter of their common name.

levels (this may be an advantage at the physiological level and not a foraging advantage). It is interesting that in the case of the wood/leopard pair, the wood frog larvae appear to be the better competitors under field conditions and are the only species able to grow and survive in low productivity woodland ponds where the forest canopy forms a complete cover over the pond (Werner and Glennemeier 1999). The leopard frog, however, is capable of faster absolute growth in more productive ponds (Werner and Glennemeier 1999). There is often such a trade-off between growth rates at low vs. high resources in a wide array of taxa (Arendt 1997). There is no evidence over the food levels we used that the curves for the wood frog and leopard frog cross, but they do converge at higher resource levels. In the case of the bullfrog and green frog we have typically found that the green frog is equal in competitive ability in the absence of predators even though less active (Werner 1991), or has a slightly greater effect on the bullfrog than the reverse (Relyea and Werner 1999). However, in the presence of predators, the bullfrog does not reduce activity to as low a level as the green frog and becomes a relatively better competitor (Werner 1991, Relyea and Werner 1999). Clearly it would be useful to partition the effects of the different components of competitive ability in these species, and

TABLE 8. ANOVA results of rate of mass change per day for each species individually.

\begin{tabular}{|c|c|c|c|c|c|c|c|c|c|c|c|c|c|}
\hline \multirow[b]{2}{*}{ Factor } & \multirow[b]{2}{*}{ df } & \multicolumn{3}{|c|}{ Bull frog } & \multicolumn{3}{|c|}{ Green frog } & \multicolumn{3}{|c|}{ Leopard frog } & \multicolumn{3}{|c|}{ Wood frog } \\
\hline & & $\begin{array}{l}\text { Sum of } \\
\text { squares }\end{array}$ & $F$ & $P$ & $\begin{array}{l}\text { Sum of } \\
\text { squares }\end{array}$ & $F$ & $P$ & $\begin{array}{l}\text { Sum of } \\
\text { Squares }\end{array}$ & $F$ & $P$ & $\begin{array}{l}\text { Sum of } \\
\text { squares }\end{array}$ & $F$ & $P$ \\
\hline Time & 1 & 0.0085 & 35.7 & $<0.001$ & 0.0003 & 1.5 & 0.22 & 0.0328 & 117.1 & $<0.001$ & 0.0361 & 63.7 & $<0.001$ \\
\hline $\begin{array}{l}\text { Food } \\
\text { availability }\end{array}$ & 1 & 0.0759 & 317.6 & $<0.001$ & 0.0990 & 501.8 & $<0.001$ & 0.1064 & 379.6 & $<0.001$ & 0.0567 & 100.1 & $<0.001$ \\
\hline $\begin{array}{l}\text { Predator } \\
\text { density }\end{array}$ & 1 & 0.0001 & 0.2 & 0.68 & 0.0003 & 1.6 & 0.21 & 0.0025 & 8.8 & 0.005 & 0.0001 & 0.26 & $5 \quad 0.61$ \\
\hline $\begin{array}{c}\text { Food } \times \\
\text { Pred }\end{array}$ & 1 & 0.0013 & 5.3 & 0.025 & 0.0018 & 9.3 & 0.003 & 0.0045 & 15.9 & $<0.001$ & 0.0004 & 0.78 & 30.38 \\
\hline $\begin{array}{l}\text { Block IN } \\
\text { Time }\end{array}$ & $6 \dagger$ & 0.0020 & 1.4 & 0.24 & 0.0035 & 1.8 & 0.074 & 0.0015 & 0.88 & 0.52 & 0.0005 & 0.14 & $\begin{array}{l}4 \quad 0.99 \\
4\end{array}$ \\
\hline Residuals & $53 \ddagger$ & 0.0127 & & & 0.0159 & & & 0.0149 & & & 0.0300 & & \\
\hline
\end{tabular}

$\dagger$ Block degrees of freedom for green frogs $=10$.

$\ddagger$ Residual degrees of freedom for green frogs $=81$. 
relate them to the responses to resources and predators that we have documented.

Standard models of predator-prey dynamics make no provision for changes in predator or prey behavior when environmental conditions change. This is in spite of a large literature which shows that predators alter their prey preferences when food availability changes (optimal foraging, reviewed in Stephens and Krebs 1986), and that prey alter their behavior when predator density changes (Sih 1987a, Lima and Dill 1990, Lima 1998). Only recently have authors begun to incorporate these more realistic considerations into their models (e.g., Ives and Dobson 1987, Sih 1987b, Abrams 1990, 1991a, 1993b, Matsuda et al. 1995, Ruxton 1995, Sutherland 1996, Fryxell and Lundberg 1998, Robinson and Wilson 1998). Interestingly, these added complexities often stabilize the models. The next, and critical, step will be to experimentally manipulate the behavior of individuals to test whether more complex models that incorporate the kind of adaptive variation in behavior observed in this study make better predictions about population dynamics than simpler models that exclude adaptive variation in behavior (Anholt 1997).

\section{ACKNOWLEDGMENTS}

Funding for the research was provided by NSF grant DEB9119948 to EEW and BRA. Data analysis and manuscript preparation were aided by Swiss Nationalfonds grant 3140476.94 and NSERC research grant OGP0138090 to BRA. We are grateful to J. M. L. Richardson, and two anonymous reviewers for their suggestions in improving the manuscript.

\section{Literature Cited}

Abrams, P. A. 1982. Functional responses of optimal foragers. American Naturalist 120:382-390.

Abrams, P. A. 1984. Foraging time optimization and interactions in food webs. American Naturalist 124:80-96.

Abrams, P. A. 1990. The effects of adaptive behavior on the type-2 functional response. Ecology 71:877-885.

Abrams, P. A. 1991a. Strengths of indirect effects generated by optimal foraging. Oikos 62:167-176.

Abrams, P. A. 1991b. Life history and the relationship between food availability and foraging effort. Ecology 72: $1242-1252$.

Abrams, P. A. 1993a. Why predation rates should not be proportional to predator density. Ecology 74:726-733.

Abrams, P. A. 1993b. Indirect effects arising from optimal foraging. Pages 255-279 in H. Kawanabe, J. E. Cohen, and K. Iwasaka, editors. Mutualism and community organisation: behavioural, theoretical, and food web approaches. Oxford University Press, Oxford, UK.

Abrams, P. A. 1995. Implications of dynamically variable traits for identifying, classifying, and measuring direct and indirect effects in ecological communities. American Naturalist 146:112-134.

Anholt, B. R. 1997. How should we test for the role of behavior in population dynamics? Evolutionary Ecology 11: 633-640.

Anholt, B. R., D. K. Skelly, and E. E. Werner. 1996. Factors modifying antipredator behavior in larval toads. Herpetologica 52:301-313.

Anholt, B. R., and E. E. Werner. 1995. Interaction between food availability and predation mortality mediated by adaptive behavior. Ecology 76:2230-2234.

Anholt, B. R., and E. E. Werner. 1998. Predictable changes in predation mortality as a consequence of changes in food availability and predation risk. Evolutionary Ecology 12: 729-738.

Arendt, J. D. 1997. Adaptive intrinsic growth rates: an integration across taxa. Quarterly Review of Biology 72:149177.

Brodie, E. D., and D. R. Formanowicz, Jr. 1983. Prey size preference of predators: differential vulnerability of larval anurans. Herpetologica 39:67-75.

Caldwell, J. P., J. H. Thorp, and T. O. Jervey. 1980. Predatorprey relationships among larval dragonflies, salamanders, and frogs. Oecologia 46:285-289.

Collins, J. P., and H. M. Wilbur. 1979. Breeding habits and habitats of the amphibians of the Edwin S. George Reserve, Michigan, with notes on the local distribution of fishes. Occasional Papers of the Museum of Zoology, University of Michigan. 686:1-34.

Dunbrack, R. L., and L. A. Giguere. 1987. Adaptive responses to the accelerating costs of movement: a bioenergetic basis for the Type III functional response. American Naturalist 130:147-160.

Eklov, P., and E. E. Werner. 2000. Multiple-predator effects on size-dependent behavior and mortality of two species of anuran larvae. Oikos 88:250-258.

Fryxell, J. M., and P. Lundberg. 1998. Individual behavior and community dynamics. Chapman \& Hall, London, UK.

Gendron, R. P., and J. E. R. Staddon. 1984. A laboratory simulation of foraging behavior: the effect of search rate on the probability of detecting prey. American Naturalist 124:407-415.

Gerritsen, J., and J. R. Strickler. 1977. Encounter probabilities, and community structure in zooplankton: a mathematical model. Journal of the Fisheries Research Board of Canada 34:73-82.

Gosner, K. L. 1960. A simplified table for staging anuran embryos and larvae with notes on identification. Herpetologica 16:183-190.

Horat, P., and R. D. Semlitsch. 1994. Effects of predation risk and hunger on the behaviour of two species of tadpoles. Behavioral Ecology Sociobiology 34:393-401.

Houston, A. I., J. M. McNamara, and J. M. C. Hutchinson. 1993. General results concerning the trade-off between gaining energy and avoiding predators. Philosophical Transactions of the Royal Society, London 341:375-397.

Ives, A. R., and A. P. Dobson. 1987. Antipredator behavior and the population dynamics of simple predator-prey systems. American Naturalist 130:431-447.

Kohler, S. L., and M. A. McPeek. 1989. Predation risk and the foraging behavior of competing stream insects. Ecology 70:1811-1825.

Lima, S. L. 1998. Stress and decision making under the risk of predation: recent developments from behavioral, reproductive, and ecological perspectives. Advances in the Study of Behavior 27:215-290.

Lima, S. L., and L. M. Dill. 1990. Behavioral decisions made under the risk of predation: a review and prospectus. Canadian Journal of Zoology 68:619-640.

Matsuda, H., P. A. Abrams, and M. Hori. 1995. The effect of adaptive anti-predator behavior on exploitative competition and mutualism between predators. Oikos 68:549559.

McCollum, S. A., and J. Van Buskirk 1996. Costs and benefits of a predator-induced polyphenism in the gray tree frog, Hyla chrysocelis. Evolution 50:583-593.

McNamara, J. M., and A. I. Houston. 1987. Starvation and predation as factors limiting population size. Ecology $\mathbf{6 8}$ : 1515-1519.

McNamara, J. M., and A. I. Houston. 1994. The effect of a change in foraging options on intake rate and predation rate. American Naturalist 144:978-1000. 
Norberg, R. A. 1981. Optimal flight speed in birds when feeding young. Journal of Animal Ecology 50:473-477.

O'Brien, W. J. 1974. The dynamics of nutrient limitation of phytoplankton algae: a model reconsidered. Ecology 55: 135-141.

Peacor, S. D., and E. E. Werner. 1997. Trait-mediated indirect interactions in a simple aquatic community. Ecology $\mathbf{7 8}$ $1146-1156$

Relyea, R. A. 1998. Phenotypic plasticity in larval anurans. Dissertation. University of Michigan, Ann Arbor, Michigan, USA.

Relyea, R. A., and E. E. Werner. 1999. Quantifying the relation between predator-induced behavior responses and growth performance in larval anurans. Ecology 80:21172124.

Robinson, B. W., and D. S. Wilson. 1998. Optimal foraging, specialization, and a solution to Liem's paradox. American Naturalist 151:223-235.

Ruxton, G. D. 1995. Short term refuge use and stability of predator-prey models. Theoretical Population Biology 47 $1-17$.

Sih, A. $1987 a$. Predators and prey lifestyles: an evolutionary and ecological overview. Pages 203-224 in W. C. Kerfoot, and A. Sih, editors. Predation: direct and indirect impacts on aquatic communities. University of New England Press, Hanover, New Hampshire, USA.

Sih, A. $1987 b$. Prey refuges and predator-prey stability. Theoretical Population Biology 31:1-12.

Skellam, J. G. 1958. The mathematical foundations underlying the use of line transects in animal ecology. Biometrics 14:385-400

Skelly, D. K. 1997. Tadpole communities. American Scientist 85:36-45.

Skelly, D. K., E. E. Werner, and S. A. Cortwright. 1999. Long term distributional dynamics of a Michigan amphibian assemblage. Ecology 80:2326-2337.

Speakman, J. R. 1986. The optimal search speed of terrestrial predators when feeding on terrestrial prey: a predictive model. Journal of Theoretical Biology 122:401-407.

S-Plus. 1997. Programmer's Guide. Version 4.0. Data Analysis Products Division, MathSoft, Seattle, Washington, USA.

Stein, R. A., and J. J. Magnuson. 1976. Behavioral responses of crayfish to a fish predator. Ecology 57:751-761.

Stephens, D. W., and J. R. Krebs. 1986. Foraging theory. Princeton University Press, Princeton, New Jersey, USA.

Sutherland, W. J. 1996. From individual behaviour to population ecology. Oxford University Press, Oxford, UK.
Tilman, D. 1982. Resource competition and community structure. Princeton University Press, Princeton, New Jersey, USA.

Tonn, W. M., C. A. Paszkowski, and I. J. Holopainen. 1992. Piscivory and recruitment: mechanisms structuring prey populations in small lakes. Ecology 73:951-958.

Travis, J., W. H. Keen, and J. Juilianna. 1985. The role of relative body size in a predator-prey relationship between dragonfly naiads and larval anurans. Oikos 45:59-65.

Van Buskirk, J., A. McCollum, and E. E. Werner. 1997. Natural selection for environmentally-induced phenotypes in tadpoles. Evolution 52:1983-1992.

Van Buskirk, J., and R. A. Relyea. 1999. Natural selection for phenotypic plasticity in larval anurans. Biological Journal of the Linnean Society 65:301-328.

Ware, D. M. 1975. Bioenergetics of pelagic fish: theoretical changes in swimming speed and ratio with body size. Journal of the Fisheries Research Board of Canada 30:787-797.

Wassersug, R. J. 1989. Locomotion in amphibian larvae (or "Why aren't tadpoles built like fishes?"). American Zoologist 29:65-84.

Wellborn, G. A., D. K. Skelly, and E. E. Werner. 1996. Mechanisms creating community structure across a freshwater habitat gradient. Annual Review of Ecology and Systematics 27:337-363.

Werner, E. E. 1991. Nonlethal effects of a predator on competitive interactions between two anuran larvae. Ecology 72:1709-1720.

Werner, E. E. 1992a. Competitive interactions between wood frog and northern leopard frog larvae: the influence of size and activity. Copeia 1992:26-35.

Werner, E. E. 1992b. Individual behavior and higher-order interactions. American Naturalist 140:S5-S32.

Werner, E. E., and B. R. Anholt. 1993. Ecological consequences of the tradeoff between growth and mortality rates mediated by foraging activity. American Naturalist 142: 242-272.

Werner, E. E., and B. R. Anholt. 1996. Predator induced behavioral indirect effects: consequences to competitive interactions in anuran larvae. Ecology 77:157-169.

Werner, E. E., and J. F. Gilliam. 1984. The ontogenetic niche and species interactions in size-structured populations. Annual Review of Ecology and Systematics. 15:393-425.

Werner, E. E., J. F. Gilliam, D. J. Hall, and G. G. Mittelbach 1983. An experimental test of the effects of predation risk on habitat use in fish. Ecology 64:1540-1548.

Werner, E. E., and K. S. Glennemeier. 1999. The influence of forest canopy cover on the breeding pond distributions of several amphibian species. Copeia 1999:1-12. 